\title{
The Respiratory Metabolism of Acanthamoeba rhysodes During Encystation
}

\author{
By R. N. BAND AND SHARON MOHRLOK \\ Department of Zoology, Michigan State University, \\ East Lansing, Michigan 48823, U.S.A.
}

(Accepted for publication 12 September 1969)

\begin{abstract}
SUMMARY
The endogenous respiration of vegetative amoebae, harvested during active growth, was similar in both the culture medium and in the high salt medium used to induce the encystation of starved amoebae. The respiration of starved amoebae and early stages of encystation was suppressed in high salt medium and stimulated when returned to the culture medium. A transient increase in respiration was observed early in encystation, while the respiration of later encystation stages decreased to the low level observed in mature cysts.

The respiratory metabolism of mitochondria isolated from encysting amoebae was similar to that of mitochondria from vegetative amoebae while cyst mitochondria exhibited little respiration. The catalase and acid phosphatase activities of amoebae increased during starvation and encystation.
\end{abstract}

\section{INTRODUCTION}

Hartmannellid amoebae, currently classified in the genus Acanthamoeba (Page, I967), are obligate aerobes during vegetative growth (Band, 1959) and during encystation (Band, 1963). The mature cyst, however, exhibits little respiratory activity (Reich, I948) and survives under anaerobic conditions (Band, I963). Electron microscope observations of the cyst (Bauer, 1967; Bowers \& Korn, 1968, 1969; Vickerman, 1962) reveal the appearance of dense areas in the mitochondria and a possible alteration in the structure of the mitochondrial cristae. These observations imply that reduced respiratory activity may be due to changes in the metabolism of the mitochondria.

This paper reports observations on the respiration of whole amoebae and isolated mitochondria during encystation. Acid phosphatase and catalase were used to estimate the activity of lysosomes and peroxisomes in amoebae and in mitochondrial fractions during encystation.

\section{METHODS}

Encystation. The methods of cultivation and the induction of encystation have been described previously (Band, 1959, 1963) for Acanthamoeba (Hartmannella) rhysodes. For the purpose of clarity, some of the observations from Band (1963) and related papers will be given below.

Amoebae were starved for $48 \mathrm{hr}$ in a filtered peptone medium which contained ro times less glucose than would support growth (PPGF). This procedure was a modification of the original method (Band, 1963) where the PPGF contained as much glucose as the culture medium (O.I M). After $48 \mathrm{hr}$ in PPGF, starved amoebae appeared 
normal but growth did not occur. Incubation for $48 \mathrm{hr}$ in PPGF, or in a defined medium (Band, 1962) with to times less glucose, was required for optimum encystation of amoebae when they were placed in a high salt medium (HSM, $0.25 \mathrm{M}-\mathrm{NaCl}, 3 \cdot 2 \mathrm{mM}-$ $\mathrm{MgCl}_{2} \cdot \mathrm{H}_{2} \mathrm{O}, 0.36 \mathrm{mM}^{-\mathrm{CaCl}_{2}}$ ). A misinterpretation by Griffiths \& Hughes (1968) indicated that the original method (Band, 1963) gave a very low per cent encystation. Although incubation of vegetative amoebae in HSM caused approximately $50 \%$ encystation (Band, I963), incubation of PPGF-starved amoebae in HSM was reported to induce approximately $100 \%$ encystation.

Before $24 \mathrm{hr}$, amoebae in the HSM resembled vegetative amoebae, but did not adhere to a glass surface and exhibited a net surface charge density similar to that of mature cysts rather than vegetative amoebae (Band \& Irvine, 1965). During this time addition of a carbon source inhibited encystation (Band, 1963). After $24 \mathrm{hr}$ the amoebae appeared round, exhibited an Alcian blue-positive surface coat and addition of a carbon source did not inhibit encystation. Cysts started to appear after $32 \mathrm{hr}$ in HSM, although the process was not completed until later. Aeration was required throughout encystation.

Respiration. Amoebae were washed once and suspended in fresh medium when the respiration medium was the same as the incubation medium, or washed twice when the respiration medium was different from the incubation medium. Respiration was determined at $30^{\circ}$ using a Clark electrode (Estabrook, ${ }^{1967}$ ) with $\mathrm{I}^{\circ} 5$ to $\mathrm{I} \cdot 75 \times 10^{6}$ amoebae/ $\mathrm{ml}$. respiration medium, or $\mathrm{I} \cdot 5$ to $2 \mathrm{mg}$. mitochondrial protein.

Fractionation. Although vegetative amoebae could be ruptured by relatively gentle means (i.e. a Teflon pestle of the Potter-Elvehjem type homogenizer) to obtain mitochondria, encysting amoebae became progressively more resistant to various disruption methods. The Teflon pestle did not rupture encysting amoebae or cysts in the HSM. Brief ultrasonic treatment or passage through a hand-operated mill (A. H. Thomas Co.) ruptured vegetative amoebae and encysting amoebae but not cysts. Cysts were ruptured with a ball mill, prolonged ultrasonic treatment or the French press (American Instrument Co.); the French press was used in the present study at $20,000 \mathrm{lbs}$. $/ \mathrm{in}^{2}$. Disruption of vegetative amoebae with the French press yielded metabolically active mitochondria at the same pressure so homogenization with the French press was not deleterious to cyst mitochondria. The differential response to methods of homogenization made it possible to remove defective forms at various stages of encystation; vegetative and dead amoebae could be removed from encysting amoebae with the Teflon pestle and encysting amoebae could be removed from cysts with the hand-operated mill.

The mitochondrial fraction was isolated at $4^{\circ}$, in general, according to the method of Schneider \& Hogeboom (I950), except that the isolation and wash medium was $0.25 \mathrm{M}$-sucrose containing $0.001 \mathrm{M}$-ethylenediaminetetraacetic acid and $0.5 \%(\mathrm{w} / \mathrm{v})$ bovine serum albumin (crystallized and lyophilized, Sigma Chemical Co.), $\mathrm{pH} \mathrm{7*4.}$ Respirometric measurements were made after adding $I \cdot 19 \mu$ mole Na adenosine- $5^{\prime}-$ diphosphate (ADP) (Sigman Chemical Co., Grade I) to $4 \mathrm{ml}$. of a respiration medium which contained $0 \cdot 225 \mathrm{M}$-sucrose, Io $\mathrm{mM}^{-\mathrm{KH}_{2}} \mathrm{PO}_{4}, 5 \mathrm{mM}-\mathrm{MgCl}_{2}, 20 \mathrm{~mm}-\mathrm{KCl}, \mathrm{pH} 7 \cdot 4$ at $30^{\circ}$; I $3 \mu$ mole $\mathrm{Na}$ succinate or $\mathrm{K} \alpha$-ketoglutarate or $80 \mu$ mole each of Na pyruvate and $\mathrm{Na}$ malate.

Acid phosphatase determinations were based on the hydrolysis of $p$-nitrophenyl phosphate (Sigma Chemical Co.) in the presence of $0.1 \%(\mathrm{v} / \mathrm{v})$ Triton X-Ioo 
(Wattiaux \& de Duve, 1956) and $0.022 \mathrm{M}-\mathrm{Na}$ citrate, $\mathrm{pH} 4.3$, expressed as $\mu$ mole $p$-nitrophenol liberated $/ \mathrm{mg}$. protein $/ \mathrm{min}$. at $37^{\circ}$. Catalase activity was determined by the change in absorption at $240 \mathrm{~m} \mu$ (Beers \& Sizer, 1952) of a $0.02 \mathrm{M}-\mathrm{H}_{2} \mathrm{O}_{2}$ solution containing $0.017 \mathrm{M}-\mathrm{KH}_{2} \mathrm{PO}_{4}+\mathrm{Na}_{2} \mathrm{HPO}_{4}$ buffer, $\mathrm{pH} 7 \cdot 0$, and the homogenate or mitochondrial fraction and expressed as $\mu$ mole $\mathrm{H}_{2} \mathrm{O}_{2}$ destroyed/mg. protein/min. at $24^{\circ}$.

Protein concentration was determined by the Folin-Ciocalteau method modified by Miller (1959).

\section{RESULTS}

Respiration of whole amoebae. The respiration of starved amoebae declined during encystation in HSM (Table I); HSM had no effect on the respiration of vegetative amoebae. The first effect of HSM on respiration was observed after the $48 \mathrm{hr}$ starvation period in PPGF which preceded incubation in HSM to induce encystation.

Table I. Respiration of Acanthamoeba rhysodes

The average of $n$ determinations ( \pm S.D.) in nmoles $\mathrm{O}_{2} / \mathrm{min} . / 10^{6}$ amoebae, with an oxygen cathode at $30^{\circ}$.

Source of amoebae

\begin{tabular}{|c|c|c|c|c|c|c|c|}
\hline \multirow{2}{*}{$\begin{array}{l}\text { Respiration } \\
\text { medium }\end{array}$} & \multirow[b]{2}{*}{$\begin{array}{l}\text { Vegetative } \\
\text { amoebae }\end{array}$} & \multirow{2}{*}{$\begin{array}{c}\text { Starved } \\
\text { amoebae* }\end{array}$} & \multicolumn{4}{|c|}{ Amoebae during encystation $(\mathrm{hr}) \dagger$} & \multirow[b]{2}{*}{ Cysts } \\
\hline & & & I to 2 & 3 to $4^{*}$ & 5 to 6 & 24 & \\
\hline Culture & $\begin{array}{l}12 \cdot 3 \pm 1 \cdot 5 \\
n=4\end{array}$ & $\begin{array}{l}12 \pm 2 \\
n=7\end{array}$ & $\begin{array}{c}13.7 \pm 3 \cdot 5 \\
n=12\end{array}$ & $\begin{array}{c}15 \cdot 5 \pm 3 \cdot 6 \\
n=16\end{array}$ & $\begin{array}{l}\mathrm{I} 3 \cdot \mathrm{I} \pm 3 \cdot 2 \\
n=8\end{array}$ & $\begin{array}{l}5 \cdot 9 \pm 2 \\
n=9\end{array}$ & $\begin{array}{l}2 \cdot 5 \pm 1 \cdot 2 \\
n=4\end{array}$ \\
\hline HSM & $\begin{array}{c}\mathbf{I} 2 \pm \mathbf{I} \cdot 8 \\
n=4\end{array}$ & $\begin{array}{l}6 \cdot 9 \pm \mathrm{I} \\
n=10\end{array}$ & $\begin{array}{l}7 \pm 2 \cdot 5 \\
n=10\end{array}$ & $\begin{array}{l}8 \cdot 9 \pm 2 \cdot 7 \\
n=10\end{array}$ & $\begin{array}{l}8 \cdot 3 \pm 3 \\
n=6\end{array}$ & $\begin{array}{l}5 \pm I \cdot 3 \\
n=6\end{array}$ & $\begin{array}{l}\mathrm{I} \cdot 8 \pm 0 \cdot 5 \\
n=4\end{array}$ \\
\hline LSM $\ddagger$ & $\begin{array}{c}10 \pm I \cdot 2 \\
n=3\end{array}$ & $\begin{array}{c}10 \pm 2 \\
n=3\end{array}$ & - & - & 一 & - & - \\
\hline Culture§ & $9 \cdot I$ & I4 & - & I 8 & - & 4 & 2 \\
\hline $\begin{array}{l}\text { Culture }+ \\
\text { KCN, o time }\end{array}$ & $9 \cdot 8$ & 22 & - & 28 & $一$ & 7 & $2 \cdot 8$ \\
\hline $\begin{array}{l}\text { Culture }+ \\
\text { KCN, } 30 \text { min. }\end{array}$ & $9 \cdot I$ & 15 & - & 24 & - & 6 & $\mathrm{I} \cdot 8$ \\
\hline
\end{tabular}

* Analysis of variance for starved amoebae and 3 to $4 \mathrm{hr}$ encysting amoebae indicated significant differences in respiration between these at the $5 \%$ level:

\begin{tabular}{|c|c|c|c|c|}
\hline & \multicolumn{2}{|c|}{ Culture } & \multicolumn{2}{|c|}{ HSM } \\
\hline & d.f. & Mean squares & d.f. & Mean squares \\
\hline Between & $\mathbf{I}$ & 60 & I & 20 \\
\hline Within & $2 I$ & $10 \cdot 5$ & I 8 & $4 \cdot 2$ \\
\hline
\end{tabular}

$\uparrow$ In high salt medium (HSM).

$\$$ Respiration in low salt medium (0.05 $\mathrm{M}-\mathrm{NaCl}$ with the divalent ions of HSM).

$\S$ Matched sets of single observations in which respiration was determined before, immediately after and $30 \mathrm{~min}$. after the addition of $8 \mu$ mole $\mathrm{KCN}$ to $4 \mathrm{ml}$. of amoebae.

During the first few hours in HSM before round forms appeared (24 hr), respiration was stimulated again if encysting amoebae were returned to the culture medium (PPG); this effect diminished later. The effect of HSM on respiration and its reversal in PPG was osmotic in origin. Incubation in a low salt medium (HSM with $\mathrm{NaCl}$ lowered to $0.05 \mathrm{M})$ did not suppress the respiration of vegetative amoebae from PPG and had no effect on the respiration of starved amoebae from PPGF (Table I). 
R. N. BAND AND S. MOHRLOK

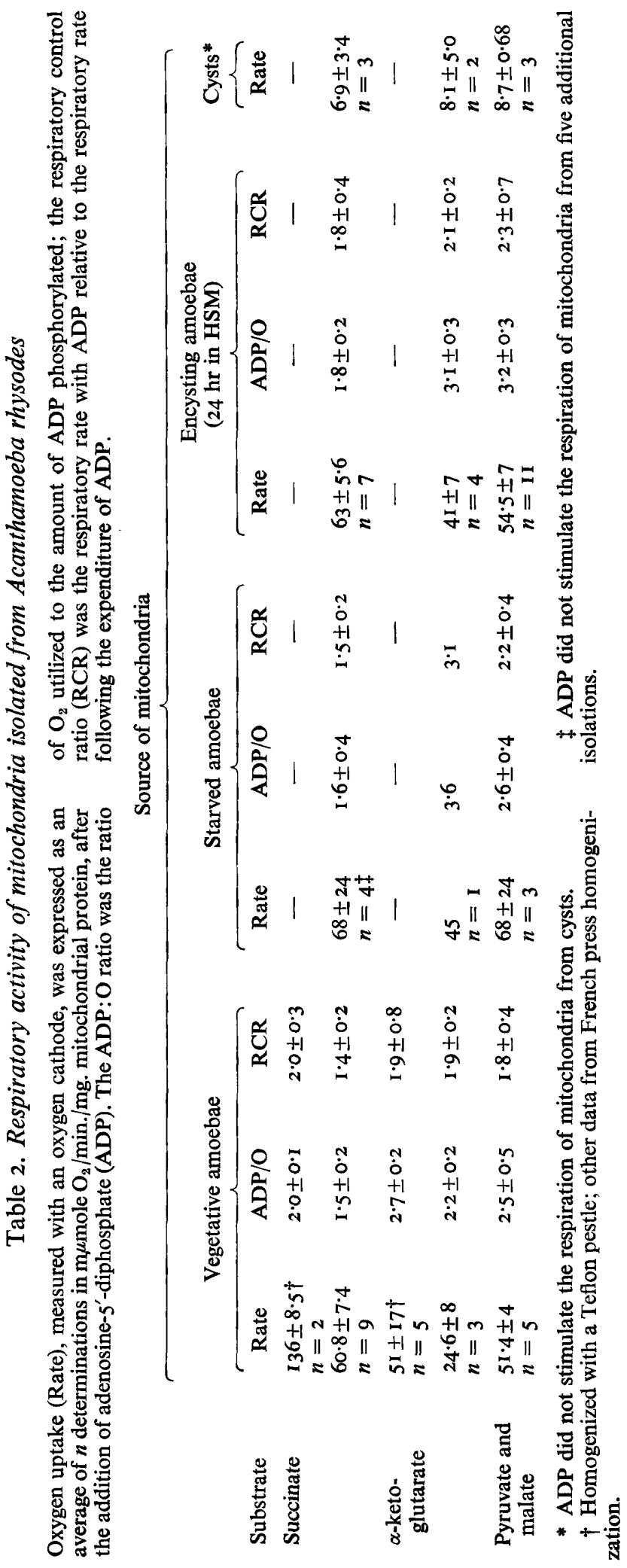


The respiration of early encystation stages increased during the first $\mathrm{I}$ to $6 \mathrm{hr}$ in HSM and then decreased to the low level exhibited by cysts (Table $\mathrm{I}$ ). This transient increase was observed with either HSM or PPG as the respiration medium and was statistically significant at the $95 \%$ level when the respiration of the PPGF-starved amoebae was compared with that of encysting amoebae after 3 to $4 \mathrm{hr}$ in HSM.

Cyanide ( $8 \mu \mathrm{mole} \mathrm{KCN} / 4 \mathrm{ml}$. of amoebae) caused an initial increase in respiration; after $30 \mathrm{~min}$. respiration returned nearly to the original rate (Table I). This was true for vegetative amoebae, starved amoebae and the various stages of encystation and cysts.

Activity of mitochondria. Vegetative mitochondria obtained using the French press were not as active as vegetative mitochondria isolated by Teflon homogenization. This difference was more apparent for the rate of respiration than for phosphorylation. The respiratory activity of mitochondria isolated from PPGF-starved amoebae was very erratic (Table 2). Many preparations of mitochondria from PPGF-starved amoebae did not exhibit respiratory control in that ADP did not stimulate respiration. The respiration rate of mitochondria from PPGF-starved amoebae was greater than that from either vegetative mitochondria or encysting amoebae.

\section{Table 3. Acid phosphatase and catalase activity of Acanthamoeba rhysodes}

Acid phosphatase activity expressed as $\mu$ mole of $p$-nitrophenol liberated $/ \mathrm{min}$. $/ \mathrm{mg}$. protein at $37^{\circ}$; catalase activity expressed as $\mu$ mole $\mathrm{H}_{2} \mathrm{O}_{2}$ destroyed $/ \mathrm{min} . / \mathrm{mg}$. protein at $24^{\circ}$. Assay procedures in Methods section; data given as an average of $n$ determinations.

\begin{tabular}{|c|c|c|c|c|}
\hline Acid phosphatase & $\begin{array}{l}\text { Vegetative } \\
\text { amoebae }\end{array}$ & $\begin{array}{c}\text { Starved } \\
\text { amoebae }\end{array}$ & $\begin{array}{l}\text { Encysting } \\
\text { amoebae* }\end{array}$ & Cysts \\
\hline Whole amoeba homogenate & $\begin{array}{l}0.6 \pm 0.08 \\
n=4\end{array}$ & $\begin{array}{l}0.8 \mathrm{1} \pm 0.17 \\
n=2\end{array}$ & $\begin{array}{l}\mathrm{I} \cdot \mathrm{O} \pm 0 \cdot \mathrm{I} \\
n=2\end{array}$ & $\begin{array}{l}0.98 \pm 0.23 \\
n=3\end{array}$ \\
\hline $\begin{array}{c}\text { Mitochondrial fraction } \\
\text { Catalase }\end{array}$ & $\begin{array}{l}0.28 \pm 0.04 \\
n=2\end{array}$ & $\begin{array}{l}0.145 \pm 0.01 \\
n=2\end{array}$ & $\begin{array}{l}0.3 \pm 0.09 \\
n=2\end{array}$ & $\begin{array}{l}0 \cdot 38 \pm 0 \cdot 1 \mathrm{I} \\
n=2\end{array}$ \\
\hline Whole amoeba homogenate & $\begin{array}{l}9 \cdot \mathrm{I} \pm 4 \\
n=4\end{array}$ & $\begin{array}{l}28 \cdot 8 \pm 8 \\
n=3\end{array}$ & $\begin{array}{l}17 \cdot 5 \pm 4 \\
n=2\end{array}$ & $\begin{array}{l}18 \cdot 3 \pm I \\
n=2\end{array}$ \\
\hline Mitochondrial fraction & $\begin{array}{l}2 \cdot 7 \pm 1 \cdot 9 \\
n=2\end{array}$ & $\begin{array}{l}\mathrm{I} 7 \cdot 6 \pm \mathrm{I} \cdot 6 \\
n=2\end{array}$ & $\begin{array}{l}6 \pm I \cdot 4 \\
n=2\end{array}$ & $\begin{array}{l}4 \cdot 3 \pm 4 \cdot 2 \\
n=2\end{array}$ \\
\hline
\end{tabular}

* In HSM for $24 \mathrm{hr}$.

Mitochondria from encysting amoebae, after $24 \mathrm{hr}$ in HSM, had respiration rates, ADP/O ratios and respiratory control similar to or greater than those of mitochondria from vegetative amoebae homogenized with the French press. Mitochondria isolated from cysts were almost inactive.

Respiratory metabolism was not changed when cytochrome c $(0.04 \mu$ mole) was added to mitochondria oxidizing succinate. When cytochrome $\mathrm{c}(0.04 \mu \mathrm{mole})$ and nicotinamide adenine dinucleotide ( $4 \mu \mathrm{mole}$ ) were added together to mitochondria from PPGF-starved amoebae oxidizing pyruvate and malate, respiration was stimulated and respiratory control was absent. These cofactors had no effect on mitochondria isolated from vegetative amoebae, encysting amoebae or cysts.

Acid phosphatase and catalase. Acid phosphatase activity in whole amoeba homogenates increased during starvation and encystation but the specific activity of acid phosphatase in the mitochondrial fractions was less than the activity in the whole 
amoeba homogenates (Table 3). Catalase activity in whole amoeba homogenates from PPGF-starved amoebae, encysting amoebae and cysts was greater than in homogenates of vegetative amoebae (Table 3); PPGF-starved amoebae were the most active. The specific activity of catalase in the mitochondrial fractions was less than the activity in whole amoeba homogenates. The mitochondrial fraction from PPGF-starved amoebae contained much greater catalase activity, however, in proportion to the activity of the whole amoeba homogenate, than did the other mitochondrial fractions.

\section{DISCUSSION}

Endogenous respiration. The observations presented in this study on the respiration of vegetative amoebae from growing cultures were similar to those reported by Reich (1948) on Acanthamoeba (Mayorella) palestinensis and by Neff, Neff \& Taylor (1958) on Neff's Acanthamoeba sp. However, A. rhysodes amoebae from actively growing cultures respired at a similar rate over a wide range of osmotic pressure (0. I5 to 0.5 osmolar in culture medium vs. HSM) while Neff et al. (I958) reported decreased respiration at elevated salt concentrations.

The sensitivity of endogenous respiration to osmotic pressure following starvation may have been the basis for using starvation to induce optimum encystation in HSM (modification from Band, 1963). The endogenous respiration of starved amoebae and early stages of encystation was reversibly suppressed in HSM. The osmotically sensitive respiratory pathway appeared to be progressively inactivated later in encystation.

The transient increase in respiration, observed during the early stages of encystation, did not appear to be osmotically sensitive since the increase was similar in HSM and in culture medium. The total endogenous respiration of mature cysts was comparable to this increase alone and was not osmotically sensitive. Thus, the transient increase in respiration may be due to the appearance of a new respiratory pathway which is responsible for the respiration of mature cysts.

Mitochondrial respiration. Mitochondria isolated from encysting amoebae did not reflect in their metabolism the changes in endogenous respiration of whole, encysting amoebae. Although the respiration of encysting amoebae after $24 \mathrm{hr}$ in HSM was not stimulated on return to a lower osmotic pressure, mitochondria isolated from them behaved similarly to vegetative mitochondria.

Electron microscope observations on the cysts of related hartmannellid amoebae (Bauer, 1967; Bowers \& Korn, 1969; Vickerman, 1962) indicated that mitochondria were retained by the cyst in a modified form. This is consistent with the present observation that mitochondria from mature cysts respired poorly and failed to exhibit respiratory control. Electron microscope observations also revealed autolysosomes and pockets of cytoplasmic debris trapped inside the cyst walls. If inert mitochondria were present in the debris, these could have been present in the mitochondrial fraction from cysts and would have distorted the data on mitochondrial metabolism. Estimates of the number of mitochondria present in the cyst's cytoplasm in a related hartmannellid amoeba (Bowers \& Korn, 1969) suggested little change in mitochondrial number from vegetative amoebae. This would favour the possibility that most of the mitochondria from the cyst in the present work came directly from the cytoplasm.

The differential centrifugation methods used to isolate mitochondria might also harvest a portion of the amoeba's lysosomes and peroxisomes. These organelles have 
been detected in hartmannellid amoebae by electron microscopy (Bowers \& Korn, 1968, 1969), by histochemistry (Müller \& Møller, 1967) and their presence suggested by chemical analysis of the culture medium (Lasman, 1967). Their presence in the mitochondrial fraction could be deleterious to the activity of isolated mitochondria and invalidate comparisons of mitochondrial activity at various stages of encystation. The activities of acid phosphatase and catalase, present in lysosomes and peroxisomes respectively (e.g. Müller, Hogg \& de Duve, I968), were similar in all fractions except the catalase activity of the mitochondrial fraction from starved amoebae. Since phosphorylation by this fraction was variable, it might have been contaminated by peroxisomes.

Effect of cyanide on respiration. The failure to inhibit respiration of vegetative, starved and encysting amoebae with cyanide did not correspond to the reports of others. At similar cyanide concentrations, vegetative amoebae of both Acanthamoeba palestinensis (Reich, 1955) and Neff's Acanthamoeba sp. (Neff et al. 1958) were inhibited in their respiration. A strict comparison of these two previous reports with observations presented in this paper was not possible as both authors used different methods and different specific amoebae. Since Reich (1955) observed a slight increase in respiration with cyanide in the presence of glucose over control amoebae without cyanide, he proposed that cyanide stimulated a respiratory pathway that utilized glucose. Since the culture conditions used by Reich (1955) and those used in the present paper were not the same, a difference in endogenous reserves may have existed. If this were true, then the amoebae in the present paper may have reacted to cyanide in a manner comparable to Reich's amoebae in the presence of glucose.

This investigation was supported by a U.S. Public Health Service Research Grant (AI-06I 17-06) from the National Institute of Allergy and Infectious Diseases.

\section{REFERENCES}

BAND, R. N. (1959). Nutritional and related biological studies on the free-living soil amoeba, Hartmannella rhysodes. J. gen. Microbiol. 2r, 80.

BAND, R. N. (1962). The amino acid requirements of the soil amoeba, Hartmannella rhysodes Singh. J. Protozool. 9, 377.

BAND, R. N. ( 1963$)$. Extrinsic requirements for encystation by the soil amoeba, Hartmannella rhysodes. J. Protozool. 10, IоI.

BAND R. N. \& IRVINE B. (1965). The electrokinetic characteristics of some small amoebae. Expl Cell Res. 39, I2I.

BAUER, H. (1967). Ultrastruktur und Zellwandbildung von Acanthamoeba sp. Vischt. naturf. Ges. Zürich I12, 173.

BEERS, R. F. \& SizER, I. W. (1952). A spectrophotometric method for measuring the breakdown of hydrogen peroxide by catalase. J. biol. Chem. 195, I33.

Bowers, B. \& KORN E. D. (1968). The fine structure of Acanthamoeba castellanii. I. The trophozoite. J. Cell Biol. 39, 95 .

BOWERs, B. \& KoRN, E. D. (1969). The fine structure of Acanthamoeba castellanii. II. Encystment. J. Cell Biol. 4r, 786.

ESTABROOK, R. W. (1967). Mitochondrial respiratory control and the polarographic measurement of ADP:O ratios. Meth. Enzym. 1o, 41 .

Griffiths, A. J. \& Hughes, D. E. (I968). Starvation and encystment of a soil amoeba Hartmannella castellanii. J. Protozool. 15, 673.

LASman, M. (1967). Observations on acid phosphatase in Mayorella palestinensis. J. cell. comp. Physiol. 69, $15 \mathrm{I}$. 
Miller, G. L. (1959). Protein determination for large numbers of samples. Analyt. Chem. 3I, 964.

Müller, M. \& Møller, M. (1967). Peroxisomes in Acanthamoeba sp. J. Protozool. 14 (suppl.), II.

Müller, M., HoGg, J. F. \& DE Duve, C. (I968). Distribution of tricarboxylic acid cycle enzymes and glyoxylate cycle enzymes between mitochondria and peroxisomes in Tetrahymena pyriformis. J. biol. Chem. 243, 5385 .

NefF, R. J., NefF, R. H. \& TAYLOR, R. E. (1958). The nutrition and metabolism of a soil amoeba, Acanthamoeba sp. Physiol. Zoöl. 31, 73.

PAGE, F. C. (1967). Re-definition of the genus Acanthamoeba with descriptions of three species. J. Protozool. 14, 709,

REICH, K. (1948). Studies on the respiration of an amoeba, Mayorella palestinensis. Physiol. Zoöl. 2r, 390.

REICH, K. (I955). The effect of cyanide and azide on the respiration of the amoeba Mayorella palestinensis. Physiol. Zoöl. 28, I45.

SCHNeIDER, W. C. \& Hogeboom, G. H. (1950). Intracellular distribution of enzymes. V. Further studies on the distribution of cytochrome $\mathrm{c}$ in rat-liver homogenates. J. biol. Chem. 183 , 123.

VICKerman, K. (1962). Patterns of cellular organization in limax amoebae. Expl Cell Res. 26, 497.

WattiauX, R. \& DE Duve, C. (I956). Tissue fractionation studies. 7. Release of bound hydrolases by means of Triton X-100. Biochem. J. 63, 606. 